\title{
Lumbar vertebra chordoma
}

A Erlank, MB ChB
J J Parsons, MB ChB
G Cilliers, MB ChB, MMed Rad (Diag)
O C Schulze, MB ChB
C Ackermann, MB ChB, MMed Rad (Diag),
MRCS (UK)
H Lameen, MB ChB
Department of Radiology, Tygerberg Hospital and
Stellenbosch University

\section{Abstract}

Spinal chordomas in the lumbar region are rare and can easily be overlooked in the differential diagnosis of vertebral column tumours.

\section{Introduction}

Spinal chordomas mostly present in association with the clivus or sacrum. We report a case where it was overlooked in the differential diagnosis of vertebral column tumours because it presented in the lumbar spine.

\section{Case}

A 66-year-old male patient presented with a longstanding history of backache, weakness of both legs, constipation and urinary incontinence; clinically he was tender over the lower thoracic and lumbar spine. Conventional $\mathrm{X}$-rays showed destruction of the pedicles of L4 and L5. On magnetic resonance imaging (MRI) a large mass was present, centred around L4. The mass involved most of the anterior elements of L4 veretebra and to a lesser extent L3 and L5. A large soft-tissue component projected anteriorly and paravertebrally, and tumour was also filling the spinal canal from L3 to S2. The tumour was heterogeneously hypointense on T1 (Fig. 1), hyperintense with multiple septae on T2 (Figs $2 \mathrm{a}$ and b) and showed diffuse nodular ring enhancement post gadolinium (Fig. 3). Biopsy confirmed a chordoma.

\section{Discussion}

Chordomas are rare tumours originating from remnants of the primitive notochord and may arise anywhere along the spinal vertebral column, being most common in a sacral or clival position (85\%). Only $6 \%$

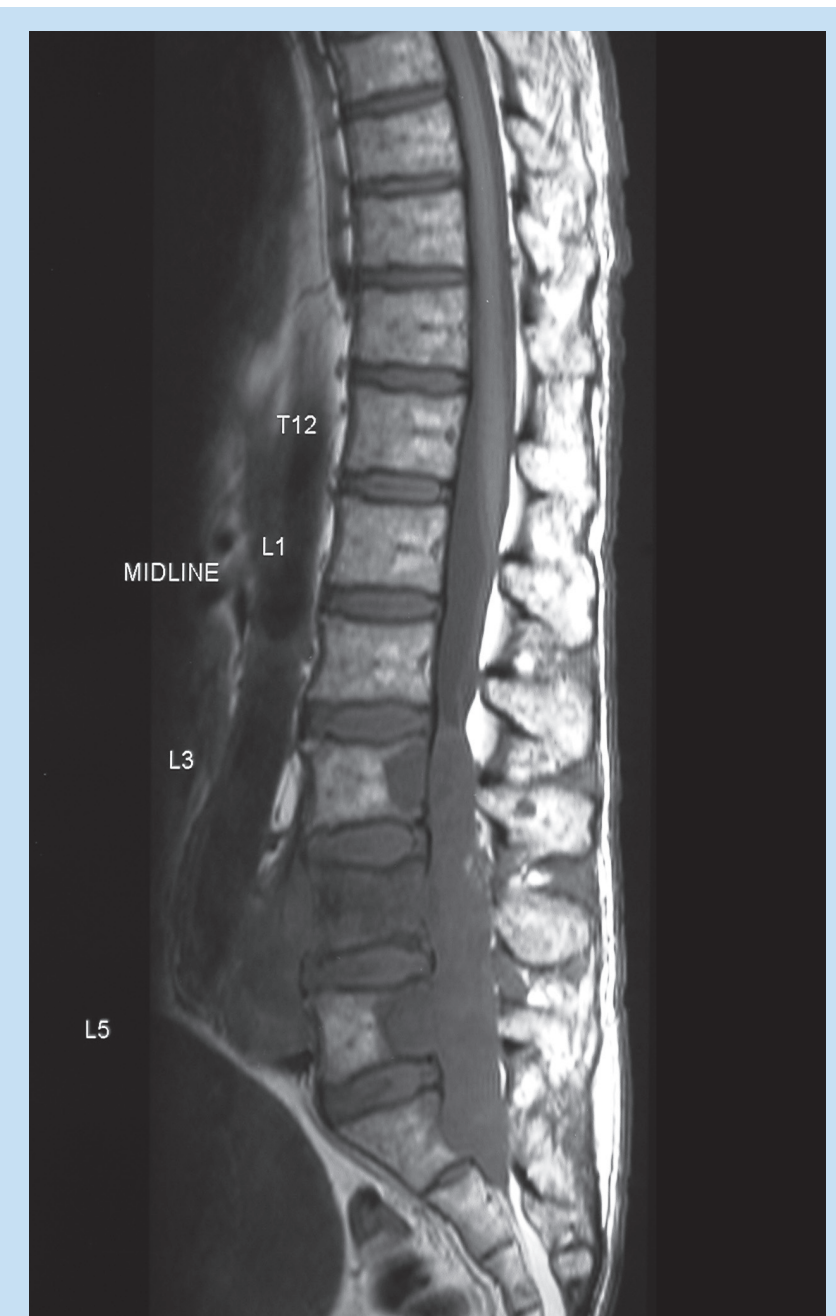

Fig. 1. T1 sagittal. Hypointense lobulated soft-tissue mass located in spinal canal destroying part of $L 3$ and $L 5$ vertebrae with complete destruction of $L 4$ vertebra. There is an additional anterior vertebral component and extension into the sacral part of the spinal canal.

of spinal chordomas originate in the lumbar region. At present, MRI is the method of choice for the diagnosis and pre-operative assessment. Chordomas are most commonly iso- or hypointense on T1-weighted images, and moderately hyperintense on $\mathrm{T} 2$-weighted images. ${ }^{1}$ Conventional X-rays show irregular and expansile vertebrae as a result of the destructive, slow-growing and reactive bone-forming nature of the tumour. ${ }^{2}$ The anterior soft-tissue mass of the involved vertebrae is the most important radiological finding and shows that prevertebral involvement is greater than osseous involvement. $^{3}$ 


\section{CASE REPORT}

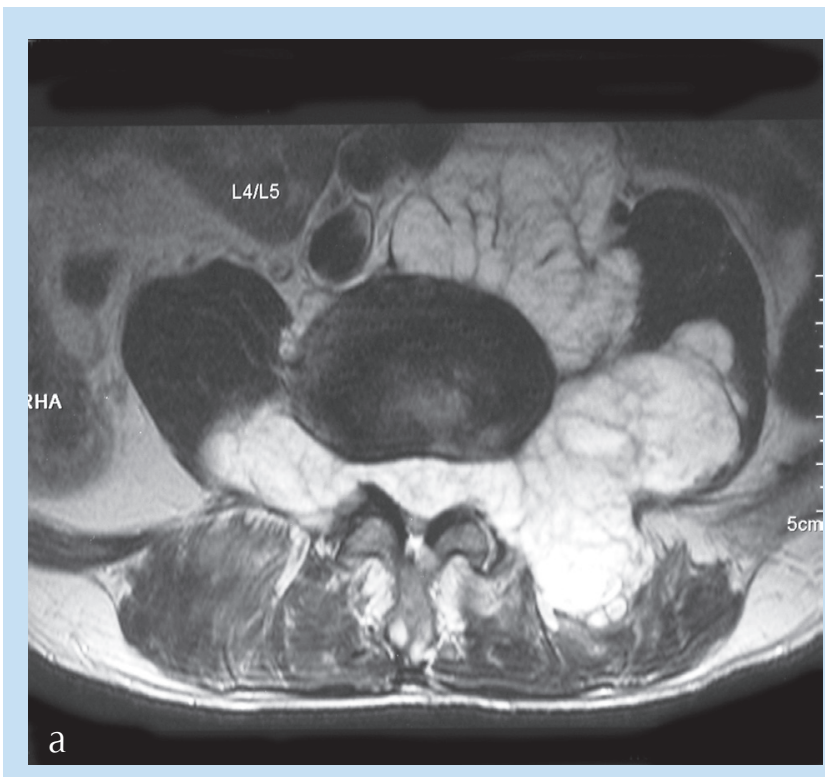

Figs 2a and b. T2 axial (a) and coronal (b). Lobulated hyperintense mass infiltrating spinal canal as well as paravertebral muscles.

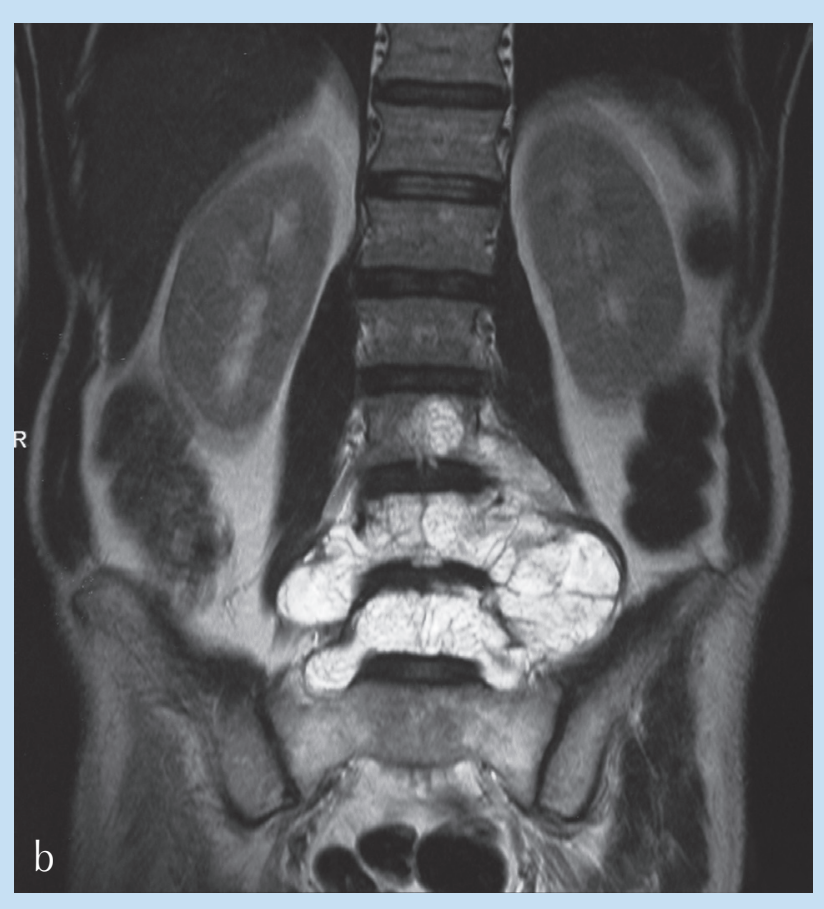

Conclusion

This case demonstrates the typical imaging features of a chordoma occurring in a rare location.

1. Bosma JJ, Pigott TJ, Pennie BH, Jaffray DC. En bloc removal of the lower lumbar vertebrae for chordoma. Report of two cases. J Neurosurgery 2001; 94(2 suppl): 284-291.

2. Mindell ER. Chordoma. J Bone Joint Surg Am 1981; 63: 501-505.

3. Sundaresan N. Chordomas. Clin Orthop 1986; 204: 135-142. 